\title{
Source of variation on lingual vibrotactile thresholds: I. The influence of experimenter experience
}

\author{
DONALD FUCCI, LINDA PETROSINO, NEAL SLOANE, and JAMES CANTRELL \\ Ohio University, Athens, Ohio 45701
}

\begin{abstract}
Ascending lingual vibrotactile thresholds were obtained from the anterior midline of the tongue for three groups of normal speaking adults. Each group was tested by a different experimenter, with varying degrees of exposure to threshold assessment techniques. The purpose of the study was to identify a potential source of variation in threshold assessment resulting from the use of the different experimenters. Results of statistical analysis revealed that different thresholds were obtained, depending on the experimenter in question. Implications of these results are discussed in reference to adequate experimenter training.
\end{abstract}

Since Fucci's original work in 1969, vibration has been successfully employed as a means for assessing oral tactile sensation. A body of research using vibrotactile stimulation has been directed toward developing equipment and methodology for the acquisition of reliable data. One of the first early concerns was possible variation in the population being tested. Telage, Fucci, and Arnst (1972) looked at intersubject variability of lingual vibrotactile thresholds obtained from a group of 110 normal-speaking adults. Data collected from two different test frequencies reflected little intersubject variability. A second parameter investigated was test-retest agreement in threshold data. Telage and Fucci (1974) looked at a single threshold trial and the median of three trials in a test-retest paradigm for 110 subjects. The median of three trials yielded slightly higher correlations than the single-trial condition did. A third subjectresponse investigation looked at practice on lingual sensory threshold values (Fucci, McCaffrey, Curtis, \& Blackmon, 1974). Twenty subjects were equally divided into two groups. The control group received procedure orientation only, and the experimental group received a 30-min practice session in threshold assessment, as well as the orientation. Results indicated that the practice group yielded lower threshold values and had smaller standard deviations than the control group had.

The preceding studies were directed toward perfecting methodology for the acquisition of consistent and reliable lingual vibrotactile threshold data. Another important variable as a source of potential variation in lingual threshold testing is the experimenter himself. The present study was designed to examine this factor by observing the performance of three experimenters who differed in amount of training prior to subject testing.

\section{METHOD}

\section{Subjects}

Thirty subjects were randomly selected from a group of 52 subjects from an introductory course in speech and hearing sciences at Ohio University. The subjects were divided into three groups of 10 for each experimental condition. The subjects ranged in age from 18 to 26 years, with a mean age of 20 years. None of the subjects reported a present or past history of speech or hearing disorders or any known sensory and/or motor impairments.

\section{Apparatus}

The equipment used in this study has been described in previous publications, the most recent being a chapter on the state of the art (Fucci \& Crary, 1979). The stimulus unit included a sine-wave generator, a frequency counter, an electronic switch-interval timer, an amplifier, a 2 -dB step variable attenuator, and an electromagnetic minivibrator. The pulsed vibratory signal generated had a $50 \%$ duty cycle (on $.5 \mathrm{sec}$ and off $.5 \mathrm{sec}$ ) with a rise and decay time of $100 \mathrm{msec}$. The measurement unit consisted of an accelerometer, a cathode follower, a microphone amplifier, and a voltmeter. A narrow-band noise generator was used to present auditory masking at $70 \mathrm{~dB}$ HTL to subjects through TDH-39 headphones.

\section{Procedure}

The procedure involved threshold data collection from three different experimenters. All three experimenters were doctoral students in speech and hearing sciences at Ohio University. Experimenter A had approximately 4 years of lingual vibrotactile threshold data collection experience. Experimenter B had no experience in lingual vibrotactile threshold data collection. However, he did have experience in audiological threshold assessment. Experimenter $\mathrm{C}$ had no experience in lingual vibrotactile threshold data collection or audiological threshold assessment.

Since it was the purpose of the investigation to look at the similarity of threshold values across experimenters, training in threshold assessment was carefully controlled. Experimenter A (experienced in vibrotactile threshold assessment) trained Experimenter B and Experimenter C. The experimenters were trained individually and received identical preliminary orientation to procedures and equipment used in lingual vibrotactile threshold testing. The experimenter training session was $1 \mathrm{~h}$ long and included (1) introduction to instrumentation and what the component parts control, (2) training instructions and procedures for subjects, (3) testing procedures for subjects, and (4) lingual vibrotactile threshold assessment of Experimenter A (the trainer).

Experimenter training occurred 1 day prior to the collection of lingual vibrotactile thresholds from any of the 10 subjects assigned to each group. All subjects within each experimenter's 
group were tested within a 3-day time span of the experimenter training session.

Prior to testing, subjects received training to acquaint them with the nature of the stimulus and to familiarize them with the testing apparatus. The subjects were trained to detect the stimulus on the tongue at a frequency of $250 \mathrm{~Hz}$. A training criterion requiring each subject to produce three threshold responses in which no two varied by more than $10 \mathrm{mV}$ was used as an index of adequate training. Subsequent to adequate training, standardized instructions were read to each subject during the testing session. Each subject was seated in an adjustable chair and asked to extend his tongue between two plastic sterilized disks. A hole in the top disk provided access of the probe to the anterior midline section of the dorsum of the tongue. The contactor area of the probe was $.128 \mathrm{~cm}^{2}$. To maintain constant pressure of the vibrator on the tongue for all subjects, the probe was lowered until a voltmeter recorded contact. The probe was lowered $1 \mathrm{~mm}$ farther into the tongue surface.

Lingual vibrotactile thresholds were obtained for each group at a frequency of $250 \mathrm{~Hz}$, since that is within the range of frequencies to which the tongue is most sensitive (Fucci, Hall, \& Weiner, 1971). Each subject was required to respond by raising his hand as soon as he detected the pulsed vibratory stimulus. An ascending psychophysical method of limits was used. The mean of three millivolt readings was accepted as the lingual threshold and was later changed to displacement in microns with the standard "g" formula for acceleration conversion.

\section{RESULTS AND DISCUSSION}

Data in microns of peak displacement were averaged for the subjects for each of the experimental and control conditions. The means and standard deviations for each condition are shown in Table 1. Mean values were strikingly similar for Experimenter A and Experimenter B, but quite different for Experimenter C. Standard deviations were similar across experimenters and were not indicative of abnormal variability. However, the standard deviation was smaller for Experimenter A.

The data were subjected to an analysis of variance for a completely randomized design to determine if significant differences existed between experimenters (Bruning \& Kintz, 1977). Table 2 shows that the main effect was significant at the .001 alpha level.

The analysis of variance procedure was followed by a Tukey test set at the .01 alpha level to determine the source of significance. These results appear in Table 3. Results show that lingual vibrotactile thresholds assessed by Experimenter $\mathrm{C}$ were significantly poorer than those obtained from Experimenters A and B. Thresholds acquired by Experimenters $\mathrm{A}$ and $\mathrm{B}$ were statistically similar.

It appears from the data that experience in threshold testing is critical for the acquisition of reliable threshold values. Although the threshold assessment experience of Experimenters A and B were in different sensory systems, both experimenters generated statistically similar threshold values. Experimenter $\mathrm{C}$ acquired statistically poorer threshold values than the other two experimenters, probably because of his total lack of experience in threshold assessment. The data suggest that specific in-depth training in vibrotactile assessment may not be necessary for the experimenter with experi-
Table 1

Threshold Means (in Microns) and Standard Deviations for Each Experimental Group

\begin{tabular}{ccc}
\hline Experimenter & Mean & SD \\
\hline A & 1.15 & .47 \\
B & 1.06 & 1.20 \\
C & 2.43 & 1.20 \\
\hline
\end{tabular}

Table 2

Summary Table for the Analysis of Variance

\begin{tabular}{lrrrr}
\hline \multicolumn{1}{c}{ Source } & SS & df & MSe & F \\
\hline Total & 28.24 & 29 & & \\
Between Groups & 11.74 & 2 & 5.87 & $9.62^{*}$ \\
Within Groups & 16.50 & 27 & .61 & \\
\hline
\end{tabular}

${ }^{*} p<.001$.

Table 3

Summary Table for the Tukey Test

\begin{tabular}{cccccc}
\hline Experimenter & df & r & q & $\begin{array}{c}\text { Critical } \\
\text { Difference }\end{array}$ & Difference \\
\hline B vs. C & 3 & 3 & 4.55 & 1.12 & $1.367^{*}$ \\
A vs. C & 3 & 3 & 4.55 & 1.12 & $1.283^{*}$ \\
A vs. B & 3 & 3 & 4.55 & 1.12 & .084 \\
\hline
\end{tabular}

*Indicates significance at .01 alpha level.

ence in threshold assessment of another sensory system. However, for the inexperienced person, there appears to be a need for adequate training and experience before collection of data. The results of this study provide a basis for further investigation into the precise determination of what might be considered adequate experimenter training for the reliable collection of data with respect to lingual vibrotactile threshold testing.

\section{REFERENCES}

Bruning, J. L., \& Kintz, B. L. Computational handbook of statistics. Glenview, Ill: Scott-Foresman, 1977.

Fucci, D. Oral vibrotactile perception: An evaluation of normal and defective speakers. Unpublished doctoral dissertation, Purdue University, 1969.

Fucci, D., \& Crary, M. A. Oral vibrotactile sensation and perception: State of the art. In Norman J. Lass (Ed.), Speech and language: Advances in basic research and practice. New York: Academic Press, 1979.

Fucci, D., Hall, D., \& Weiner, F. Normative study of oral and non-oral structures using vibrotactile stimuli. Perceptual and Motor Skills, 1971, 33, 1099-1105.

Fucci, D., McCaffrey, P., Curtis, A., \& Blackmon, R. Oral vibrotactile stimulation: A study of practice effect. Bulletin of the Psychonomic Society, 1974, 3, 209-211.

Telage, K., \& Fucci, D. Concerning intrasubject measurements of successive lingual vibrotactile responses. Perceptual and Motor Skills, 1974, 39, 1047-1052.

Telage, K., Fucci, D., \& ArNst, D. Normative study of oral vibrotactile sensitivity. Perceptual and Motor Skills, 1972, 35, 671-676. 